\title{
A statistical study over Europe of the relative locations of lightning and associated energetic burst of electrons from the radiation belt
}

\author{
F. Bourriez ${ }^{1}$, J.-A. Sauvaud ${ }^{1}$, J.-L. Pinçon ${ }^{2}$, J.-J. Berthelier ${ }^{3}$, and M. Parrot ${ }^{2}$ \\ ${ }^{1}$ IRAP, Institut de Recherche en Astrophysique et Planétologie, Toulouse, France \\ ${ }^{2}$ LPC2E/CNRS, Laboratoire de Physique et Chimie de l'Environnement et de l'Espace, Orléans, France \\ ${ }^{3}$ LATMOS/CNRS/UVSQ/UPMC, Laboratoire Atmosphères, Milieu, Observations Spatiales, Guyencourt, France \\ Correspondence to: J.-A. Sauvaud (jsauvaud@irap.omp.eu) \\ Received: 11 May 2015 - Revised: 14 December 2015 - Accepted: 11 January 2016 - Published: 1 February 2016
}

\begin{abstract}
The DEMETER (Detection of Electro-Magnetic Emissions Transmitted from Earthquake Regions) spacecraft detects short bursts of lightning-induced electron precipitation (LEP) simultaneously with newly injected upgoing whistlers. The LEP occurs within $<1 \mathrm{~s}$ of the causative lightning discharge. First in situ observations of the size and location of the region affected by the LEP precipitation are presented on the basis of a statistical study made over Europe using the DEMETER energetic particle detector, wave electric field experiment, and networks of lightning detection (Météorage, the UK Met Office Arrival Time Difference network (ATDnet), and the World Wide Lightning Location Network (WWLLN)). The LEP is shown to occur significantly north of the initial lightning and extends over some $1000 \mathrm{~km}$ on each side of the longitude of the lightning. In agreement with models of electron interaction with obliquely propagating lightning-generated whistlers, the distance from the LEP to the lightning decreases as lightning proceed to higher latitudes.
\end{abstract}

Keywords. Ionosphere (particle precipitation; waveparticle interactions) - meteorology and atmospheric dynamics (lightning)

\section{Introduction}

Cyclotron-resonant loss of trapped electrons via scattering by lightning whistler waves was first indirectly evidenced as whistler-associated perturbations of subionospheric very low-frequency (VLF) signals (Helliwell et al., 1973) and then directly detected (Voss et al., 1984, 1998) as lightning- induced electron precipitation bursts associated with ducted whistlers.

In a subsequent study, Inan et al. (2007) show that large regions of enhanced background precipitation are produced and maintained by high rates of lightning within a localized thunderstorm.

Analysis of the DEMETER (Detection of ElectroMagnetic Emissions Transmitted from Earthquake Regions) spacecraft particle data showed that energetic electron precipitation exhibits a seasonal dependence consistent with lightning-induced electron precipitation. Over the United States, energetic electron fluxes in the slot region (between $L=2$ and 3) are significantly higher in the northern summer than in the winter, consistent with the seasonal variation of lightning activity in the Northern Hemisphere (Gemelos et al., 2009)

According to the model by Abel and Thorne (1998), electron scattering near the peak of the inner zone, $L=1.65$, is dominated by VLF transmitter waves. At $L=2.4$, diffusion by the lightning-generated $(4.5 \mathrm{kHz})$ waves provides the dominant scattering process near the loss cone. By $L=3.2$, cyclotron resonance interactions with plasmaspheric hiss can occur, and these naturally generated waves provide the dominant scattering loss process throughout the outer portion of the slot region (Abel and Thorne, 1998; Lyons et al., 1972).

Despite wave propagation models showing the expected location of the lightning-induced electron precipitation (LEP) events relative to the location of the lightning (Lauben et al., 1999, 2001), no direct statistical study to experimentally determine the exact relative location of the two phenomena made it possible. The DEMETER spacecraft and ground-based lightning networks are used to infer such a 


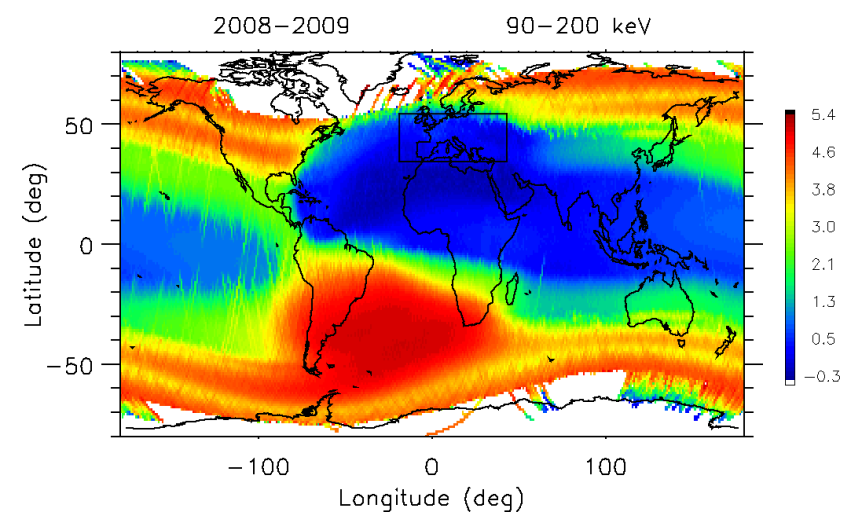

Figure 1. Geographical distribution of the electron integral flux between 90 and $200 \mathrm{keV}$ at $700 \mathrm{~km}$ at pitch angles close to $90^{\circ}$. The region selected over Europe to study the relationship between LEP and lightning is indicated by a black box. At the highest latitudes the large fluxes signal the outer radiation belt. Generally, the satellite does not deliver data at magnetic latitudes higher than $65^{\circ}$. However, in several cases coordinated studies have been performed with ground-based auroral observatories. The corresponding passes can be seen over Scandinavia, Greenland, and Alaska, as well as over the conjugate regions. The region of high fluxes located around latitudes of $55^{\circ}$ at a longitude of $-180^{\circ}$ corresponds to the slot. The European region at latitudes lower than those of Scandinavia shows a weak background due to the fact that quasi-trapped electrons precipitate inside the South Atlantic anomaly. The faint electron fluxes over southern Australia extending eastward are the signature of the effect of the North West Cape (NWC) VLF transmitter.

distribution. The region from $L=2$ to 3 was selected. Europe appears to be a region where the electron flux background is weak at $700 \mathrm{~km}$ altitude due to the presence of the South Atlantic Anomaly (SAA) west of it, as shown in Fig. 1, which gives the distribution of electron integral flux in the energy range 90-200 keV averaged over 2008 and 2009. Furthermore, several lightning networks are available in Europe, so the study presented here focuses on this region. The DEMETER energy range from 90 to $200 \mathrm{keV}$ is well adapted to study the resonant interaction of radiation belt electrons with VLF waves in the frequency range from 4 to $10 \mathrm{kHz}$ at $L$ values around 2.5 (see Koons et al., 1981). Lightning instances and locations, detected by ground-based lightning detection networks, have been precisely determined as a source of electron precipitation, and for the first time, we have established, statistically and on a case-by-case basis, the position of electron precipitation events caused by lightning-generated whistlers. LEP events can occur over a range of several to $1500 \mathrm{~km}$ north of the causative lightning and spread westward and eastward over $1000 \mathrm{~km}$. Furthermore, in good agreement with numerical simulations, this analysis clearly shows the tendency for electron precipitation bursts to be closer to the causative lightning with increasing latitude. Note that the direct method used here is complementary to the measurements of subionospheric VLF signals at multiple sites used to assess the spatial distribution and occurrence of ionospheric disturbances (Trimpi events) associated with lightning-induced electron precipitation (Helliwell et al., 1973; Inan et al., 1990).

\section{Data}

DEMETER was in a $700 \mathrm{~km}$ altitude, polar and circular sun-synchronous orbit (Parrot, 2006). The DEMETER data used for this paper come from two different instruments: (1) the Instrument for Detection of Particles (IDP) (Sauvaud et al., 2006), measuring energetic electron fluxes with a 1 and $4 \mathrm{~s}$ time resolution for burst and survey mode, respectively, and in the energy range of $72.9 \mathrm{keV}$ to $2.35 \mathrm{MeV}$ in 256 steps with a $17.8 \mathrm{keV}$ energy resolution and (2) the Electric Field Instrument (ICE), measuring electromagnetic fields up to $20 \mathrm{kHz}$ in burst mode (Berthelier et al., 2006). The lightning position, timing, and peak current, when available, are provided by the following ground-based lightning detection networks: the World Wide Lightning Location Network (WWLLN; USA), South Africa Weather Service (SAWS), European Cooperation for Lightning Detection (EUCLID)-Météorage (EU), and Arrival Time Difference network (ATDnet; UK). ATDnet data were available for 2004 to 2011, whereas EUCLID-Météorage data were available for 2007 to 2008. WWLLN data have an average resolution over Europe; this led us to generally prefer the local ATDnet database for reported cases. However, ATDnet data do not provide intensity and polarity lightning features; therefore, we determined causative lightning peak currents from the EUCLID-Météorage database for cases reported for 2007 to 2008.

\section{Observations}

DEMETER data were used to search for LEP bursts over Europe for the entire mission period, i.e., from 2004 to 2010. Such an example of short bursts of electron fluxes up to $200 \mathrm{keV}$, detected on 9 October 2007, is displayed in Fig. 2a in the IDP data (first and third panel from the top), with strong whistlers in ICE data (second panel from the top) associated with strong lightning peak intensity (fourth panel from the top). Figure $2 b$ shows the simultaneous position of lightning and the satellite. High-frequency lightning thunderstorms are present during that day, with 148 lightning strokes between 20:48:00 and 20:49:30 UT. Two active cells trigger electron precipitation over Germany, with one located offshore of Corsica, the other in southern Italy. This precipitation of electrons presents flux enhancements over a wide energy range in IDP spectra and a clear peak in integral fluxes (90.7 to $250.9 \mathrm{keV}$ ), while ICE spectra shows intense $0+$ whistlers. The electromagnetic wave emitted by lightning is called a radio atmospheric, or sferic for short. The energy of a sferic is primarily concentrated in the VLF band. A sferic can propagate over long distances through the waveguide formed 
(a) 06 October 2007

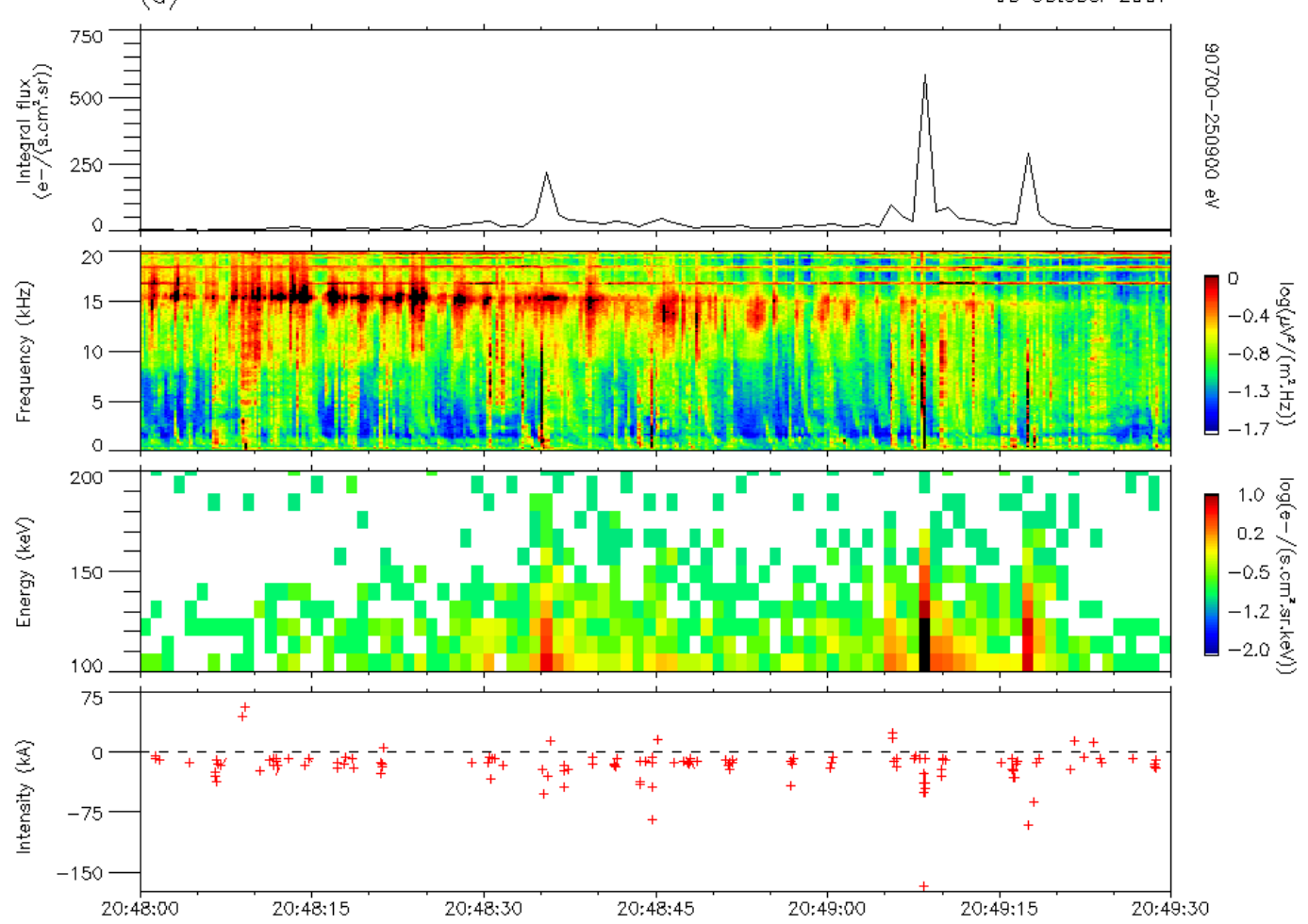

(b)

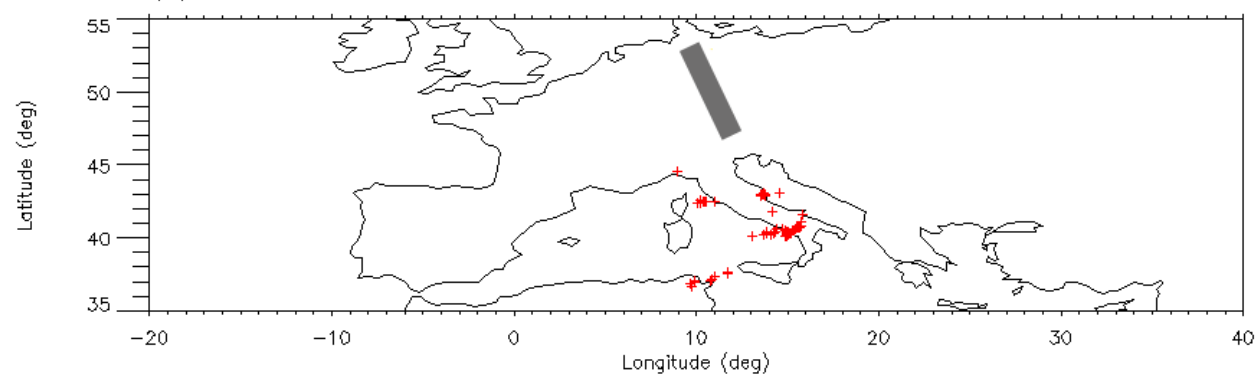

Figure 2. Several LEPs corresponding to an intense storm activity over the Mediterranean region on 6 October 2007. Panel (a): from top to bottom: integral electron energy flux from 90 to $250 \mathrm{keV}$; wave-frequency-time spectrogram between 0 and $20 \mathrm{kHz}$; energy-time electron spectrogram from 100 to $200 \mathrm{keV}$; lightning peak currents from Météorage. Panel (b): location of intense lightning activity (red crosses) and the trajectory of the spacecraft (grey) when LEPs are detected.

between the Earth and the ionosphere. A small fraction of the sferic energy escapes the waveguide and travels in the whistler mode, and the resulting waves are called whistlers. The initial upgoing wave is specifically termed a $0+$ whistler to signify that it has crossed the equator zero times and is propagating up into the magnetosphere. The LEP burst detected at 20:49:08 UT is associated with an intense 0+ whistler and very intense causative lightning strokes, with a maximum at $-167.3 \mathrm{kA}$. Lightning peak currents highlight the role of CG- (cloud-to-ground) lightning strokes in trigger-generated whistler electron precipitation. There is quite a large difference between the spacecraft latitude and that of the causative lightning. This is a general rule and, for example, two similar burst of electrons were recorded on- board the DEMETER satellite over Germany on 2 September 2005, triggered by several CG- lightning flashes for one and by CG+ lightning for the other burst, located in northern Italy (Inan et al., 2007). Sometimes, indeed, an LEP burst detected onboard the DEMETER satellite was associated with a sprite, as on 17 November 2006 when 17 sprites were observed that day, all associated with CG+ lightning (Parrot et al., 2013).

In order for the DEMETER data to be selected as a correlated LEP and lightning event, the following set of strict criteria had to be fulfilled simultaneously:

- DEMETER had to be located between 35 and $55^{\circ}$ latitude and -20 to $40^{\circ}$ longitude, and thunderstorms had 


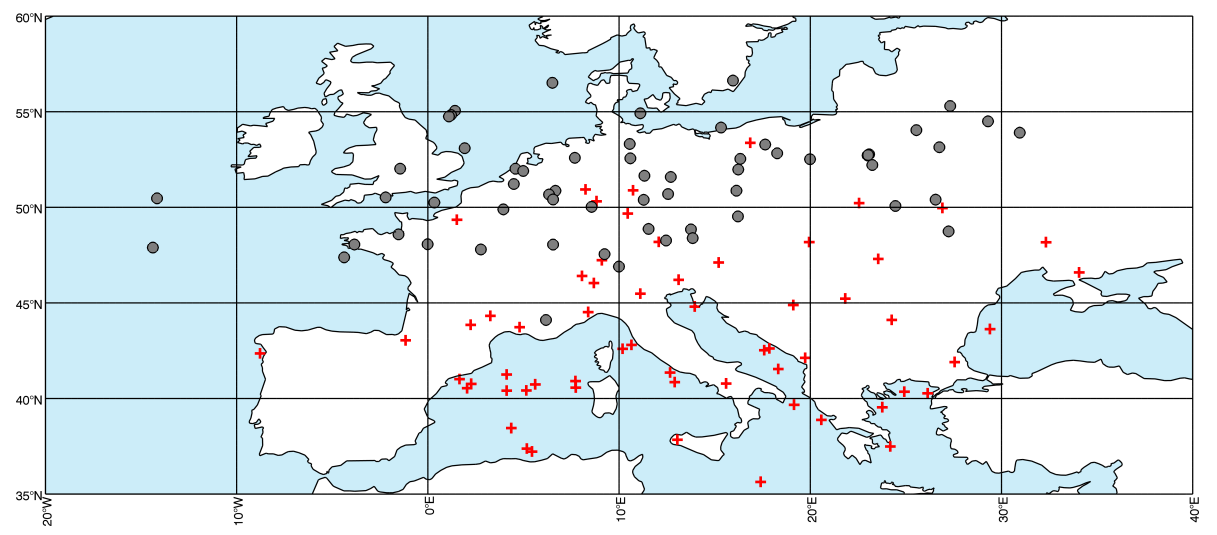

Figure 3. Locations of lightning (red crosses) and the associated satellite coordinates corresponding to the detection of LEPs (grey dots).

to be active within this region at this time, in order to rely on detailed ATDnet and Météorage lightning data.

- The electron fluxes observed onboard DEMETER have to display short bursts in the energy range between 90 and $200 \mathrm{keV}$. An integral electron flux between 90 and $250 \mathrm{keV}$ (where cyclotron resonance between electrons and Whistlers in the $5 \mathrm{kHz}$ range is expected), which is greater than $50-60 \mathrm{e}^{-} \mathrm{cm}^{-2} \mathrm{~s}^{-1} \mathrm{sr}^{-1}$ (well above the background) and short or occasionally of several seconds' duration, accounts for an LEP event.

- On board DEMETER, the time occurrence of the electron burst (minimum recorded duration of $1 \mathrm{~s}$ in burst mode) has to follow the time occurrence of whistlers within $0.6 \mathrm{~s}$ (see Peter and Inan, 2004).

- The time occurrence of the whistlers observed on board DEMETER must coincide with lightning detected on ground (parent lightning) within $0.2 \mathrm{~s}$, given the fact that lightning propagates at the speed of light. Note that the time resolution for the wave measurements is $0.2 \mathrm{~s}$.

- The latitude of the parent lightning must not differ by more than $15^{\circ}$ from that of the spacecraft in order to reject non-correlated impulsive events.

Note that a $0.4-0.6 \mathrm{~s}$ time delay represents the expected duration between the lightning-generated whistler and the interaction with radiation belt electrons, which precipitate into the ionosphere (Peter and Inan, 2004). LEP events, in which several distant and simultaneous thunderstorms and the causative lightning position could not be clearly determined, have been excluded.

By using this methodology, we found 60 clear DEMETER observations of electron precipitation events related to lightning over Europe (Fig. 3). Considering the large number of LEPs at times characterized via subionospheric VLF signal perturbations (e.g., 80 and 81 LEPs for two $4 \mathrm{~h}$ periods; Peter and Inan, 2004), the number of events presented here is relatively small. This is mostly due to the strict rules used during the selection process and the limitation of the IDP, which cannot detect energies lower than $90 \mathrm{keV}$. All LEP events are located between 40 and $60^{\circ}$ latitude, which corresponds to $1.5<L<3$. Associated lightning is always located at a lower latitude. The LEP distribution is in overall good agreement with the results of previous numerical simulations by Abel and Thorne (1998), showing that LEP represents the primary radiation belt electron loss process at $L<2.5$. Figure 4 shows the seasonal climatology of these events (black) and the seasonal climatology normalized by the instances of lightning occurring in the LEP-generated lightning domain (grey). The seasons are defined as the meteorological seasons in the Northern Hemisphere. Regarding the seasonal climatology, there is a greater occurrence of LEP during summer and autumn than during the rest of the year. However, the normalized climatology presents a greater occurrence of these events during winter than summer. It means that even if more lightning occurs over land during summer, more LEP events are detected during winter inside the region of interest. This is probably due to the fact that LEPs over Europe are mostly initiated by lightning occurring over the Mediterranean, which has been shown to be more frequent during winter (Anderson and Klugmann, 2014). Furthermore, LEPs generated by lightning over land may occur at $L \approx 3$ and then may be undetected inside the outer radiation belt electron background fluxes.

Lightning-satellite latitudinal and longitudinal distances relative to the parent lightning are shown in Fig. 5. Spatial distributions account for a longitudinal distribution that is slightly biased to the east from the lightning position, whereas the latitudinal distribution is directly north of the lightning position. Note that a $100 \mathrm{keV}$ electron only drifts at a rate of $1^{\circ} \min ^{-1}$ at $L=2$, which preclude an eastward drift as a possible explanation for the eastward displacement. Thus, this means that the LEPs detected by DEMETER tend to be located to the northeast of thunderstorms. The events presented here clearly show that LEPs occur only 


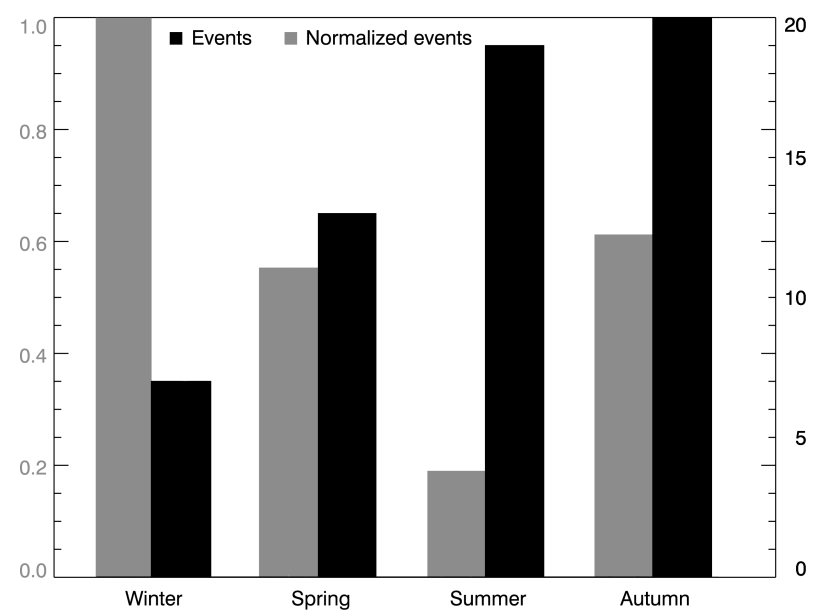

Figure 4. Seasonal distribution (black) and seasonal normalized distribution (grey) of the detected lightning-LEP events. The seasonal distribution has been normalized by the seasonal total number of lightning flashes occurring over the domain and scaled according to the winter season.
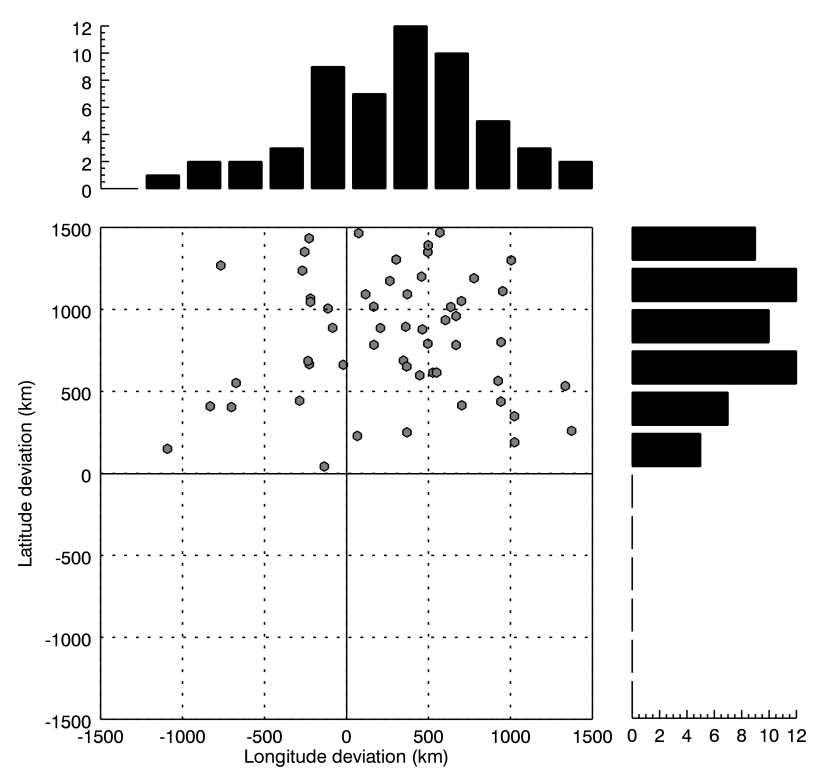

Figure 5. Spatial distribution of the latitudinal and longitudinal lightning-satellite distance with latitudinal and longitudinal histograms.

north of the storm, with a lightning-satellite mean distance of $1014.6 \pm 378.5 \mathrm{~km}$, a satellite mean latitude of $51.3 \pm 2.6^{\circ}$, and a lightning mean latitude of $43.6 \pm 4.0^{\circ}$. Note that the distance between the lightning and the satellite is calculated at a $100 \mathrm{~km}$ altitude along the great circle between the satellite geomagnetic footprint and the lightning coordinates.

Figure 6a gives the lightning latitude as a function of the lightning-satellite distance. Note that lightning-satellite distances are greater at lower than at higher latitudes. The solid line gives the best fit, while $1 \sigma$ and $2 \sigma$ confidence levels
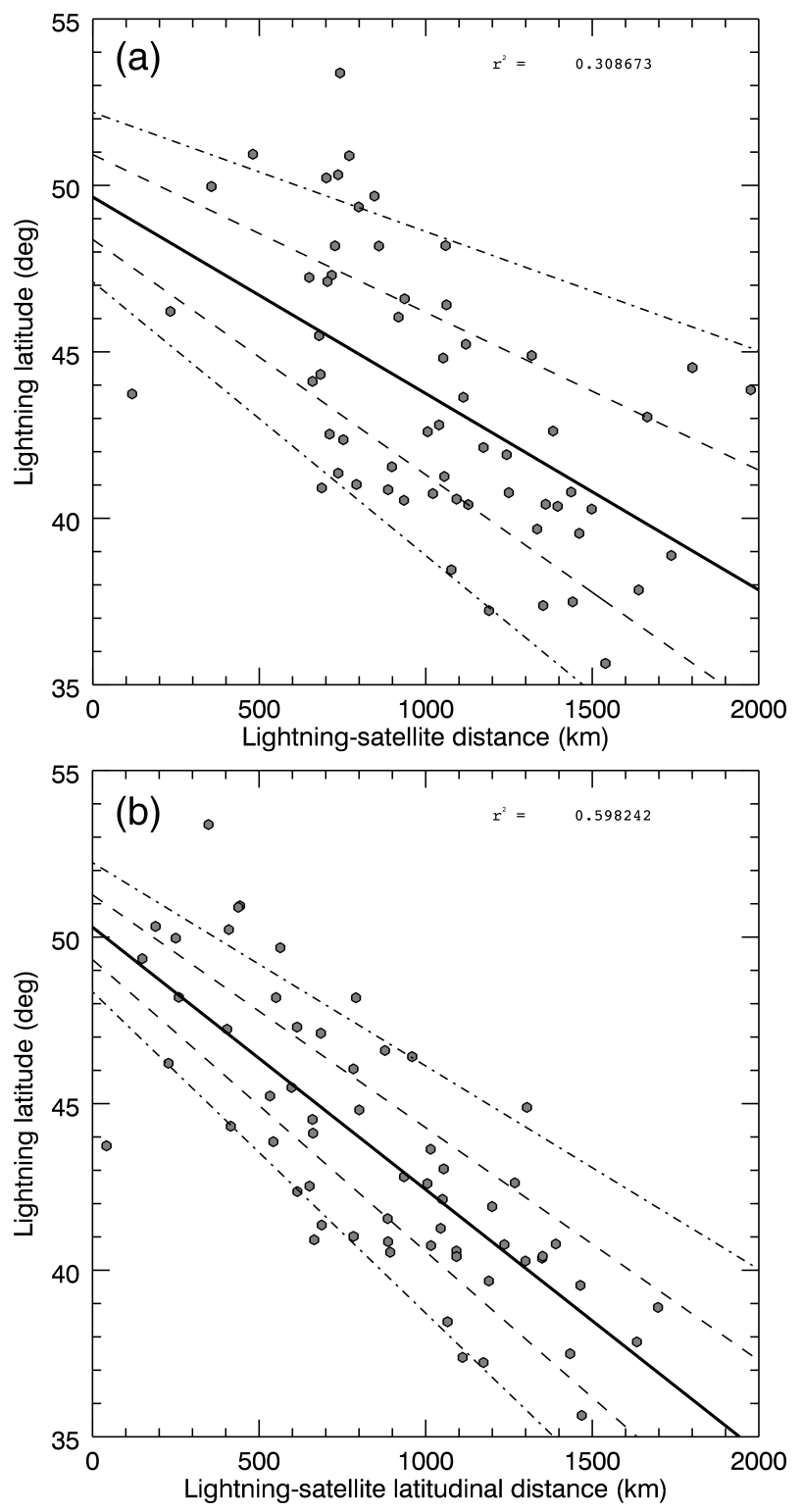

Figure 6. Panel (a): lightning latitude (deg) vs. lightning-satellite distance $(\mathrm{km})$. Panel (b): lightning latitude (deg) vs. latitudinal lightning-satellite distance $(\mathrm{km})$. The solid line represents the linear regression, the dashed line the confidence limits at $\pm 1 \sigma(68 \%)$, and the dash-dot line the confidence limits at $\pm 2 \sigma(95 \%)$.

are displayed by dashed and dot-dashed lines, respectively. There is a general trend for the distance between the lightning and the LEP to increase for low latitudes of lightning. However, the experimental points are dispersed and the correlation coefficient $r^{2}$ is only 0.309 . Figure $6 \mathrm{~b}$ presents the lightning latitude as a function of the lightning-LEP latitudinal distance, i.e., the longitudinal displacement is not taken into account. In Fig. 6b, the correlation coefficient $r^{2}$ increases to 0.598 , showing that the difference of latitude between lightning and satellite is quite well correlated with the 

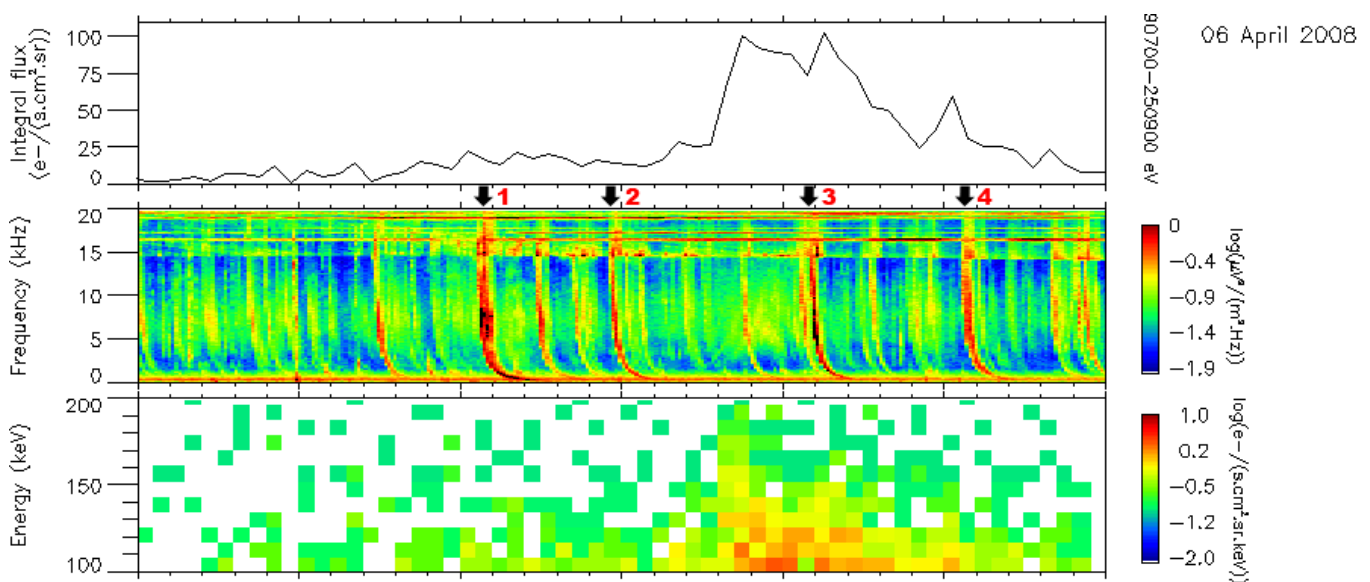

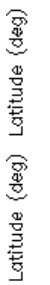
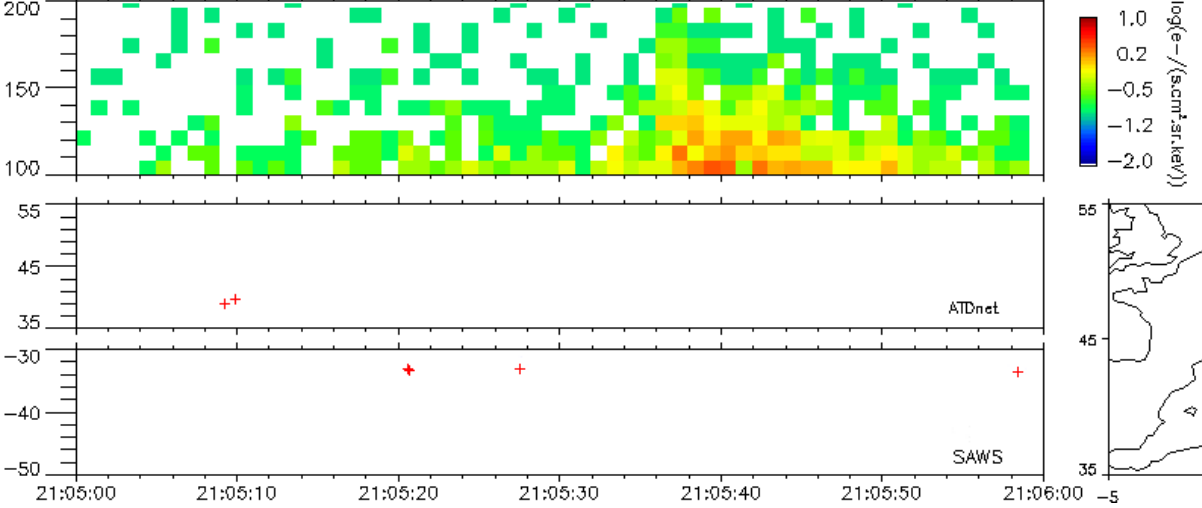

Figure 7. LEP over Europe associated with an active storm in the geographical conjugate area on 6 April 2008. From top to bottom: integral electron energy flux from 90 to $250 \mathrm{keV}$; wave-frequency-time spectrogram between 0 and $20 \mathrm{kHz}$ (the arrows indicate four intense whistlers); energy-time electron spectrogram from 100 to $200 \mathrm{keV}$; lightning occurrences from ATDnet; lightning occurrences from SAWS. The map shows the trajectory of the spacecraft (grey) when LEP are detected.

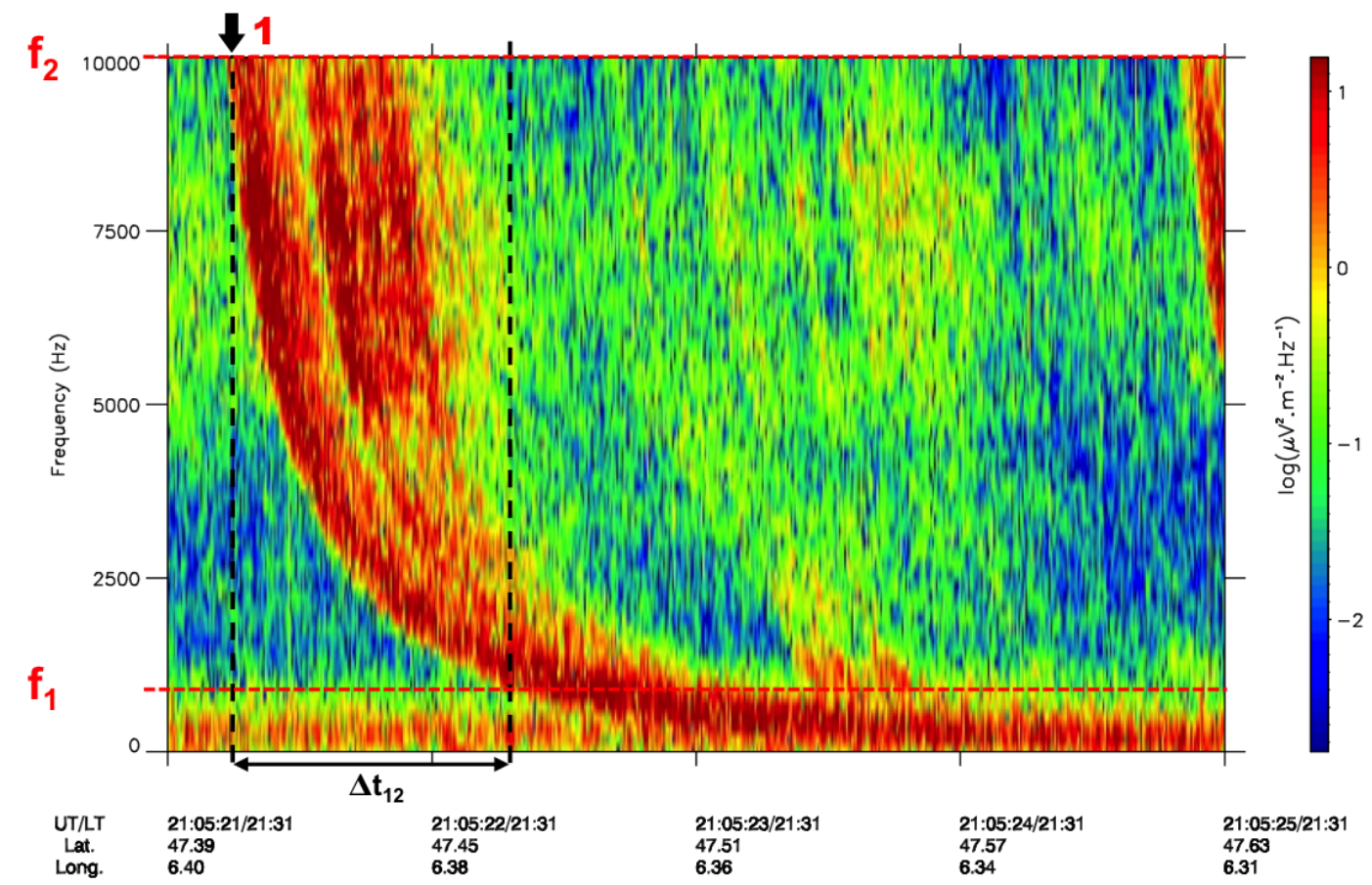

Figure 8. High-resolution ICE data VLF spectrogram up to $10 \mathrm{kHz}$ at the time of the three simultaneous lightning strokes and the associated whistler (1) in Fig. 7. The vertical and horizontal dashed lines correspond to the time and the frequency difference, respectively, used to compute the dispersion parameter $D_{0}$ of the whistler (see text). 
latitude of the lightning. LEP and lightning are separated by $900-1700 \mathrm{~km}$ at lightning latitudes lower than $40^{\circ}$ and by less than $1200 \mathrm{~km}$ at lightning latitudes higher than $45^{\circ}$. This decrease is probably related to the tighter field-line convergence at higher $L$-shells.

Furthermore, from time to time, bursts of energetic electrons are observed on board DEMETER without corresponding lightning activity over Europe. For example, on 6 April 2008, an enhanced precipitation flux period was observed over France on board DEMETER with no lightning activity detected by the ATDnet network (Fig. 7). No 0+ whistlers are observed at the time of this event, but instead 13 whistlers with a relatively long dispersion are observed between 21:05:00 and 21:06:00 UT. The observation of welldispersed whistlers and no $0+$ whistlers during this event, and the lack of thunderstorm activity over Europe at this time is consistent with lightning sources located in the Southern Hemisphere. Collier et al. (2006) have revealed this phenomenon from a study of whistlers detected over eastern Europe generated by lightning over southern Africa (see also Burgess and Inan, 1989, 1990, 1991). Regarding the lightning activities in the geographical conjugate area preceding the electron precipitation period, SAWS data emphasize a lightning activity offshore of southern Africa, with three simultaneous discharges and then an individual one associated with intense whistlers at 21:05:20.268, 21:05:20.311, 21:05:20.359, and 21:05:27.279 UT. Among the whistlers shown in Fig. 7, four are of particular interest as they do not show a noticeable attenuation in intensity in the lower part of the VLF frequency range corresponding to the Earthionosphere cutoff. It means that these whistlers had almost no propagation in the Earth-ionosphere waveguide before reaching DEMETER. It is thus possible for these four whistlers to indicate, with a reasonable precision, the location of the lightning sources.

Let us first check that the characteristics of the selected whistlers are compliant with ducted propagation along the field line. To achieve this goal we take into account the general form of Eckersley's law: $t=D(f) f^{-1 / 2}$ (Eckersley, 1935; Gurnett et al., 1990). For frequencies much smaller than the nose frequency, one can show that the approximation $D(f)=D_{0}=$ constant is valid. At the time of the observations, DEMETER was on $L=2.3$ field line which corresponds to a nose frequency greater than $30 \mathrm{kHz}$ (Lichtenberger, 2009). Hereafter, we limit our study to the frequency range $[0 ; 10] \mathrm{kHz}$, and accordingly we use a simplified Eckersley's law $t=D_{0} f^{-1 / 2}$. The values of the dispersion parameters $D_{0}$ associated with the selected whistlers can be determined from the shape of the VLF spectrograms provided by the ICE experiment on board DEMETER. The VLF spectrogram of the whistler labeled (1) in Fig. 7 is presented in Fig. 8. By selecting two frequencies $-f_{1}(1 \mathrm{kHz})$ and $f_{2}$ $(10 \mathrm{kHz})$ - and measuring the time difference $\Delta t_{12}(1.08 \mathrm{~s})$, the corresponding $D_{0}$ parameter can be calculated. The computed $D_{0}$ is identical for the four whistlers considered and equal to $50 \mathrm{~s}^{1 / 2}$. This value is fully compliant with the expected value for a $L=2.3$ field line (Lichtenberger, 2009). Consequently, the characteristics of the observed whistlers are compatible with whistlers propagating along the magnetic field line and coming from the Southern Hemisphere. Using International Geomagnetic Reference Field (IGRF) modeling of the Earth magnetic field, we found the magnetic conjugate latitudes of the four whistlers to be about $-37^{\circ}$, while the latitude of the lightning observed close to the Indian Ocean coast of South Africa is $-33^{\circ}$. Both the dispersion parameter and the conjugate latitudes of the four whistlers suggest that the lightning parents are from the Southern Hemisphere. Considering, furthermore, the number of whistlers, it is most likely that the enhanced precipitation flux measured during the spacecraft pass was triggered by lightning activities in the conjugate hemisphere that have been partially detected there by ground networks.

\section{Discussion}

Complementary measurements of energetic electrons and VLF waves performed simultaneously on board DEMETER allowed us to unambiguously determine the occurrence of electron short bursts associated with whistlers. More rarely, we were able to relate these events to lightning whose position is given by ground-based networks. In about 60 cases, the identification of the exact position of the lightning, not only that of the storm cell, was possible based on relative timings. The analysis of the database clearly shows that the electron precipitation in the energy range of 90 to $200 \mathrm{keV}$ is located north of the parent lightning in a wide region with an average difference in latitude reaching up to $7.7 \pm 3.6^{\circ}$. This result is in good agreement with models of wave propagation and of their interaction with the electrons from the radiation belt, either considering ducted or non-ducted whistlers (Inan and Carpenter, 1986; Lauben, 1998; Lauben et al., 1999). The $1 \mathrm{~s}$ time resolution of the energetic particle detector available on board DEMETER is not sufficient to allow for a statistical study of the propagation of the precipitation location as a function of the time elapsed since the initial lightning.

\section{Conclusion}

A statistical study of lightning distribution associated with spontaneous electron precipitation has been carried out. A total of 60 instantaneous clear lightning-induced electron precipitation have been detected by DEMETER during passes over Europe. The study shows that lightning leads to electron precipitation over a very large area located north of lightning up to $1500 \mathrm{~km}$. This area spreads over $1000 \mathrm{~km}$ on both sides of the causative lightning. A clear correlation between the lightning latitude and the lightning-satellite latitudinal distance has been highlighted and is in good agreement with whistler-wave propagation models and their interactions with 
radiation belt electrons (Lauben et al., 2001). Furthermore, ducted-whistler-generated electron precipitation detected by DEMETER over France and associated with lightning activities in the conjugate hemisphere has been found. These results appear to confirm previous indirect studies using the ionospheric perturbations measured by VLF transmitters and receivers and caused by high-energy electron precipitation associated with lightning.

Acknowledgements. We thank the World Wide Lightning Location Network, the UK Met Office, Météorage, and the South Africa Weather Services for providing the lightning data.

The topical editor, S. Milan, thanks two anonymous referees for help in evaluating this paper.

\section{References}

Abel, B. and Thorne, R. M.: Electron scattering loss in Earth's inner magnetosphere 1. Dominant physical processes, J. Geophys. Res., 103, 2385-2396, doi:10.1029/97JA02919, 1998.

Anderson, G. and Klugmann, D.: A European lightning density analysis using 5 years of ATDnet data, Nat. Hazards Earth Syst. Sci., 14, 815-829, doi:10.5194/nhess-14-815-2014, 2014.

Berthelier, J. J., Godefroy, M., Leblanc, F., Malingre, M., Menvielle, M., Lagoutte, D., Brochot, J.-Y., Colin, F., Elie, F., Legendre, C., Zamora, P., Benoist, D., Chapuis, Y., Artru, J., and Pfaff, R.: ICE, the electric field experiment on DEMETER, Planet. Space Sci., 54, doi:10.1016/j.pss.2005.10.016, 456-471, 2006.

Burgess, W. C. and Inan, U. S.: Simultaneous lightning-associated precipitation of radiation-belt electrons into the Northern and Southern Hemispheres, Antarctic J., 24 , 271-272, 1989.

Burgess, W. C. and Inan, U. S.: Simultaneous disturbance of conjugate ionospheric regions in association with individual lightning flashes, Geophys. Res. Lett., 17, 259-262, doi:10.1029/g1017i003p00259, 1990.

Burgess, W. C. and Inan, U. S.: Ducted whistlers and the burst loss of radiation belt electrons to geomagnetically conjugate ionospheric regions, Antarctic J., 26, 309-311, 1991.

Collier, A. B., Hughes, A. R. W., Lichtenberger, J., and Steinbach, P.: Seasonal and diurnal variation of lightning activity over southern Africa and correlation with European whistler observations, Ann. Geophys., 24, 529-542, doi:10.5194/angeo-24-529-2006, 2006.

Eckersley, T. L.: Musical atmospherics, Nature, 135, 104-105, 1935.

Gemelos, E. S., Inan, U. S., Walt, M., Parrot, M., and Sauvaud, J. A.: Seasonal dependence of energetic electron precipitation: Evidence for a global role of lightning, Geophys. Res. Lett., 36, L21107, doi:10.1029/2009GL040396, 2009.

Gurnett, D. A., Kurth, W. S., Cairns, I. H., and Granroth, L. J.: Whistler in Neptune's magnetosphere: Evidence of atmospheric lightning, J. Geophys. Res., 95, 20967-20976, doi:10.1029/JA095iA12p20967, 1990.

Helliwell, R. A., Katsufrakis, J. P., and Trimpi, M. L.: Whistlerinduced amplitude perturbation in VLF propagation, J. Geophys. Res., 78, 4679-4688, doi:10.1029/JA078i022p04679, 1973.
Inan, U. S. and Carpenter, D. L.: On the correlation of whistlers and associated subionospheric VLF/LF perturbations, J. Geophys. Res., 91, 3106-3116, doi:10.1029/JA091iA03p03106, 1986.

Inan, U. S., Knifsend, F. A., and Oh, J.: Subionospheric VLF "imaging" of lightning-induced electron precipitation from the magnetosphere, J. Geophys. Res., 95, 17217-17231, doi:10.1029/JA095iA10p17217, 1990.

Inan, U. S., Piddyachiy, D., Peter, W. B., Sauvaud, J. A., and Parrot, M.: DEMETER satellite observations of lightninginduced electron precipitation, Geophys. Res. Lett., 34, L07103, doi:10.1029/2006GL029238, 2007.

Koons, H. C., Edgar, B. C., and Vampola, A. L.: Precipitation of inner zone electrons by whistler mode waves from the VLF transmitters UMS and NWC, J. Geophys. Res., 86, 640-648, doi:10.1029/JA086iA02p00640, 1981.

Lauben, D. S.: Precipitation of Radiation Belt Electrons by Obliquely-Propagating Lightning-Generated Whistler Waves, Ph.D. Dissertation, Stanford University, Stanford, CA, USA, 1998.

Lauben, D. S., Inan, U. S., and Bell, T. F.: Polewarddisplaced electron precipitation from lightning-generated oblique whistlers, Geophys. Res. Lett., 26, 2633-2636, doi:10.1029/1999GL900374, 1999.

Lauben, D. S., Inan, U. S., and Bell, T. F.: Precipitation of radiation belt electrons induced by obliquely propagating lightninggenerated whistlers, J. Geophys. Res., 106, 29745-29770, doi:10.1029/1999JA000155, 2001.

Lichtenberger, J.: A new whistler inversion method, J. Geophys. Res., 114, A07222, doi:10.1029/2008JA013799, 2009.

Lyons, L. R., Thorne, R. M., and Kennel, C. F.: Pitch-angle diffusion of radiation belt electrons within the plasmasphere, J. Geophys. Res., 77, 3455-3474, doi:10.1029/JA077i019p03455, 1972.

Parrot, M.: Special issue: First results of the DEMETER micro-satellite, Planet. Space Sci., 54, 411-558, doi:10.1016/j.pss.2005.10.012, 2006.

Parrot, M., Sauvaud, J. A., Soula, S., Pinçon, J. L., and van der Velde, O.: Ionospheric density perturbations recorded by DEMETER above intense thunderstorms, J. Geophys. Res.-Space, 118, 5169-5176, doi:10.1002/jgra.50460, 2013.

Peter, W. B. and Inan, U. S.: On the occurrence and spatial extent of electron precipitation induced by oblique nonducted whistler waves, J. Geophys. Res., 109, A12215, doi:10.1029/2004JA010412, 2004.

Sauvaud, J. A., Moreau, T., Maggiolo, R., Treilhou, J. P., Jacquey, C., Cros, A., Coutelier, J., Rouzaud, J., Penou, E., and Gangloff, M.: High energy electron detection onboard DEMETER: The IDP spectrometer, description and first results on the inner belt, Planet. Space Sci., 54, 502-511, doi:10.1016/j.pss.2005.10.019, 2006.

Voss, H. D., Imhof, W. L., Walt, M., Mobilia, J., Gaines, E. E., Reagan, J. B., Inan, U. S., Helliwell, R. A., Carpenter, D. L., and Katsufrakis, J. P.: Lightning-induced electron precipitation, Nature, 312, 740-742, doi:10.1038/312740a0, 1984.

Voss, H. D., Walt, M., Imhof, W. L., Mobilia, J., and Inan, U. S.: Satellite observations of lightning-induced electron precipitation, J. Geophys. Res., 103, 11725-11744, doi:10.1029/97JA02878, 1998. 